\title{
HIGHLY COMPACT MICRO-MACHINED COPLANAR BANDPASS FILTER
}

\author{
K. Grenier, P. Pons*, R. Plana, J-L. Cazaux***, C. Boulanger**, T. Parra and J. Graffeuil \\ Université P. Sabatier, 118 Route de Narbonne, 31062 TOULOUSE, FRANCE \\ *LAAS / CNRS, 7 av. du Colonel Roche, 31077 TOULOUSE cedex 4, FRANCE \\ 푱 +33(0)561336922, fax.+33(0)561336969, grenier@laas.fr \\ **CNES, 18 av. Edouard Belin, 31055 TOULOUSE cedex, FRANCE \\ ***Alcatel Space Industries, 26 av. J-F. Champollion, 31037 TOULOUSE cedex, FRANCE
}

\begin{abstract}
Highly compact micro-machined coplanar bandpass filters based on end-coupled half-wavelength and quarter-wavelength resonators topologies have been investigated. Simple gap and interdigitated capacitive discontinuities have been modeled through an appropriate technique and have been implemented in order to achieve low loss and narrow bandpass membrane micromachined filters. Excellent performances, similar to the state of the art, together with an important improvement in term of compactness have been achieved.
\end{abstract}

\section{INTRODUCTION}

The wireless millimeter wave local area networks are challenging the more conventional communications systems using opto-electronic transmission regarding the electrical performance, the environment adaptability and, of course, the cost. Advances achieved in the epitaxy techniques allow to realize silicon based devices featuring frequency performance up to $100 \mathrm{GHz}$ through silicongermanium heterostructures [1]. One problem related to the silicon technology was the ability to implement passive elements featuring a high quality factor. This can be achieved by using micro-machining capabilities [2]. In a microwave or millimeter wave receiver, one crucial issue deals with the performance of the filtering cells which are very bulky and commonly "off chip" realized. According to the future "System on Chip" requirements, we propose some alternative issues allowing the realization of a monolithic silicon based filtering section. In this field, the coplanar waveguide technology is gaining more and more interest due to its easier technological realization as well as its better compatibility with a "flip chip" or high frequency monolithic integration. Therefore it has been retained for filter realization.
Several studies have already been focused on the CPW bandpass filters [3-7]. The two major issues are compactness improvements and transmission losses reduction.

In this paper, we report on a filter in the $60 \mathrm{GHz}$ range which both presents low loss and high compactness. In order to get a narrow bandpass filter with low loss, we chose the end-coupled halfwavelength resonators topology [7] associated with a membrane CPW micro-machined technology. Section II will focus on a brief overview of the technological process. Section III will address the design methodology that has been implemented. In section IV, we will present the experimental results obtained on the CPW micro-machined bandpass filter.

\section{TECHNOLOGICAL PROCESS DESCRIPTION}

The technological process involved in this paper deals with a CPW micro-machined silicon based technology derived from the work developed at Michigan University [8]. It is based on the elaboration of a two-layer $\mathrm{SiO}_{2} / \mathrm{Si}_{\mathrm{x}} \mathrm{N}_{\mathrm{y}}(8000 \AA / 6000 \AA)$ membrane optimized with respect to its intrinsic strain. In order to get an accurate control of the dimensions and shape factor of the metallizations, we developed a specific technological process, derived from the LIGA one, where electroplated gold conductors are realized within a photoresist mould achieved from conventional UV equipment. The membrane is then released through an anisotropic etching of silicon in potassium hydroxyde solution $(\mathrm{KOH})$ allowing properties similar to those obtained in a free space [9]. More details on the technological process could be found in [10].

The next section will focus on the filter design used to realize bandpass filter in the $60 \mathrm{GHz}$ range. 


\section{FILTER METHOD}

A conventional filter's synthesis method has been developed to design the end-coupled half-wavelength resonators filter [11]. It involves an equivalent electrical representation shown in figure 1a, where the admittance inverters $J_{\mathrm{ij}}$ and the lines' length $\lambda_{\mathrm{o}} / 2$ are determined from the filter gauge.
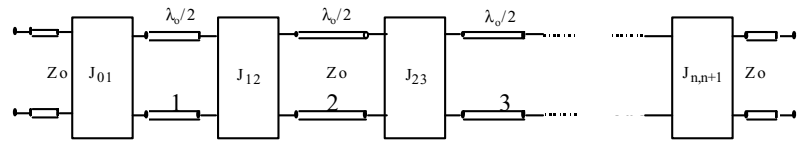

(a)

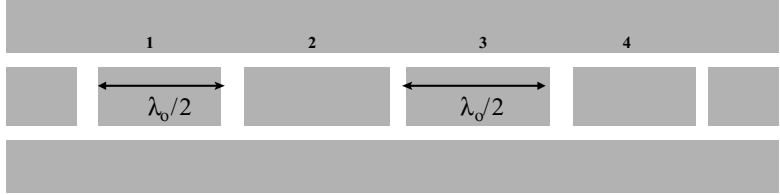

(b)

Figure 1. a) Schematic and b) coplanar layout of an end-coupled $\lambda / 2$ resonators filter.

In coplanar technology, admittance inverters can be achieved by opening gaps in the inner conductor, creating a capacitively coupled resonant section. The coplanar implementation is shown in figure $1 \mathrm{~b}$.

In order to get an equivalence between the admittance inverters electrical characteristics and their corresponding layout dimensions, we used an electrical model of the discontinuity given in figure 2 .

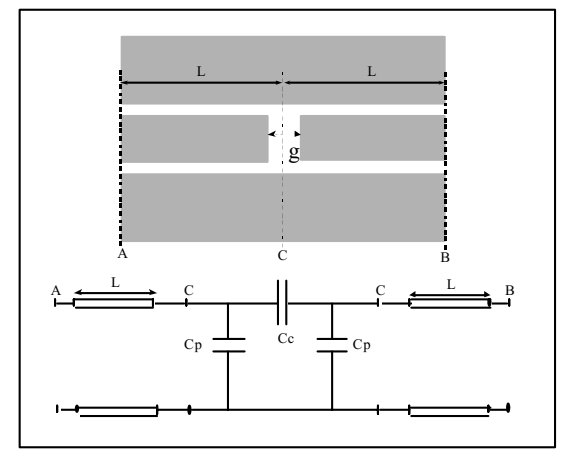

Figure 2. Electrical model of the discontinuity.

Thanks to electromagnetic simulations realized through the 2.5D SONNET software, we obtained each equivalent electrical elements by computation of the cascade matrix $(\mathrm{ABCD})_{\text {comp. }}$. By de-embedding the CPW lines on both sides of the discontinuity defined by their cascade matrices $(A B C D)_{\text {line }}$, we derived the gap cascade matrix $(\mathrm{ABCD})_{\text {gap }}$ assuming the following expression :

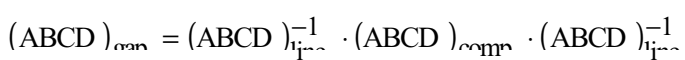

The confrontation between the theoretical cascade matrix of the $\Pi$ capacitive circuit shown in figure 2 and the one issued from the calculation (1) leads to the two simple equations (2-3) written below :

$$
\begin{aligned}
& \mathrm{Cc}=\frac{\mathrm{B}_{\text {gap }}}{\mathrm{j} \cdot \boldsymbol{\omega}} \\
& \mathrm{Cp}=\mathrm{Cc} \cdot\left(\mathrm{A}_{\text {gap }}-1\right)
\end{aligned}
$$

where $\mathrm{B}_{\text {gap }}$ and $\mathrm{A}_{\text {gap }}$ are the coefficients of the cascade $(\mathrm{ABCD})_{\text {gap }}$ matrix. A similar work has also been achieved for an interdigitated gap (see figure 3 ).

The capacitor $\mathrm{C}_{\mathrm{c}}$ is shown in figure 3 together with $\mathrm{C}_{\mathrm{c}}$ exp obtained from $\mathrm{S}$ parameters measurements on different structures specially processed to this end.

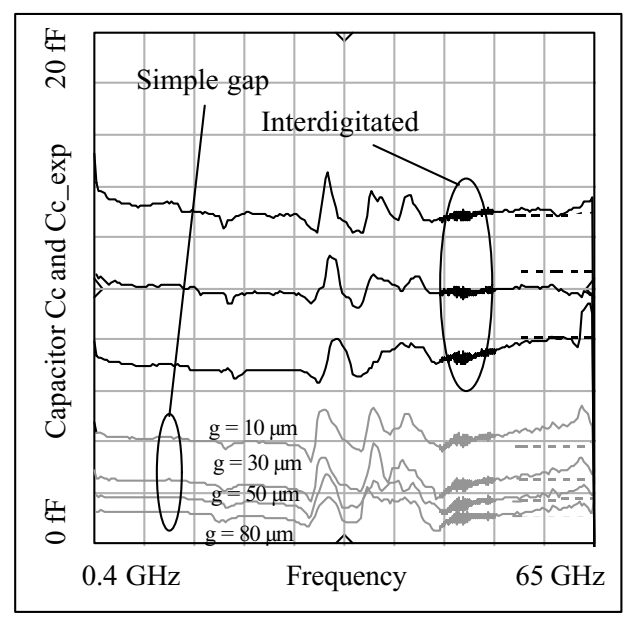

Figure 3. Measured and computed coupling capacitor $\mathrm{Cc}$ versus the frequency for simple and interdigitated gaps.

Dashed lines represent computed $\mathrm{Cc}$ obtained from eq. (2) between 55 and $65 \mathrm{GHz}$. Figure 3 shows a good agreement between calculated and measured data and substantiates our approach. Similar results are obtained for $\mathrm{Cp}$. Therefore we are able to compute $\mathrm{Cc}$ and $\mathrm{Cp}$ for any gap dimension and to synthesize any admittance inverters [11].

From the filter gauge, we have found that a second order filter, similar to the one shown in figure 4, needs a very strong coupling at the filter input and output and a very weak coupling at the center of the filter.

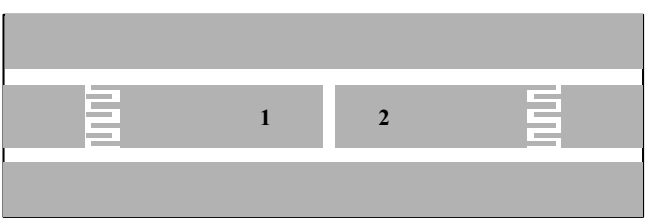

Figure 4. Coplanar 2 poles bandpass filter layout. 
A simple gap is not able to provide a strong coupling unless the central conductor is very wide, which cannot be practically realized if the dimensions must be taken as small as possible. Therefore, we used interdigitated input and output gaps which satisfy compactness requirements.

\section{RESULTS AND CONCLUSIONS}

Thanks to our previous investigations, the successful design of several passband filters has been achieved. Table 1 shows the measured performance of an order 2 and an order 4 filter. As micro-machined membrane structures transmission performance essentially relies on conductor losses, increasing filter's order (eg. increasing the filter's length) really damages the performance. Thus, an order above 2 is not recommended if we consider the poor performances of the higher order filter.

Table 1 : Different order's filters performances with $\lambda / 2$ resonators.

\begin{tabular}{|c|c|c|c|c|c|c|}
\hline Order & $\begin{array}{c}\mathrm{S} 21_{\mathrm{fo}} \\
(\mathrm{dB})\end{array}$ & $\begin{array}{c}\text { fo } \\
(\mathrm{GHz})\end{array}$ & Q1 & Qu & $\begin{array}{c}\text { Surface } \\
\left(\mathrm{mm}^{2}\right)\end{array}$ & $\begin{array}{c}\mathrm{S}_{1} 1_{\mathrm{fo}} \\
(\mathrm{dB})\end{array}$ \\
\hline $\mathrm{n}=2$ & -2.7 & 57.7 & 14.7 & 55 & 7.6 & -33 \\
\hline $\mathrm{n}=4$ & -4.4 & 56.2 & 14.8 & 37 & 13.5 & -21.5 \\
\hline
\end{tabular}

The second order filter presents an insertion loss of $2.7 \mathrm{~dB}$ at $57 \mathrm{GHz}$ with a $7 \%$ bandwidth which is near from the state of the art [12]. The loaded quality factor (Q1) is in the range of 15 while a value in the range of 50 has been obtained for the unloaded quality factor $(\mathrm{Qu})$. An important feature is the compactness of the filter, which is about $7.6 \mathrm{~mm}^{2}$, more than 3 times better with respect to previous realizations [12].

This result can be further improved by using a $\lambda / 4$ end-coupled resonator filter with both dual admittance and impedance inverters [4]. In order to realize such structures, we have also investigated impedance inverters.

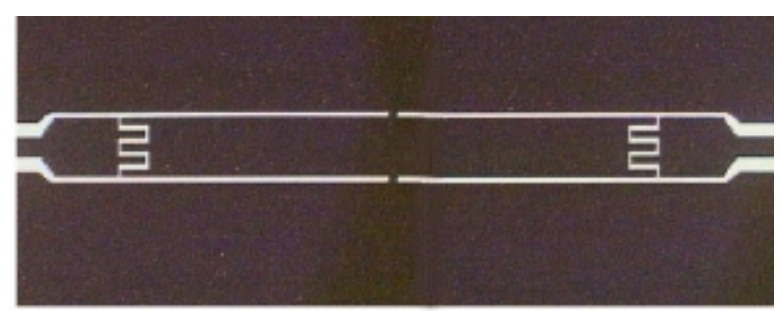

Figure 5. $\lambda / 4$ end-coupled filter photography.

They are realized using short circuits between the central conductor and the coplanar grounds. They are equivalent to a $\mathrm{T}$ inductive model. A second order $\lambda / 4$ filter (see figure 5) using impedance and admittance inverters has therefore been synthesized, processed and measured.

Its performance is compared with the previous filter in figure 6 and table 2.

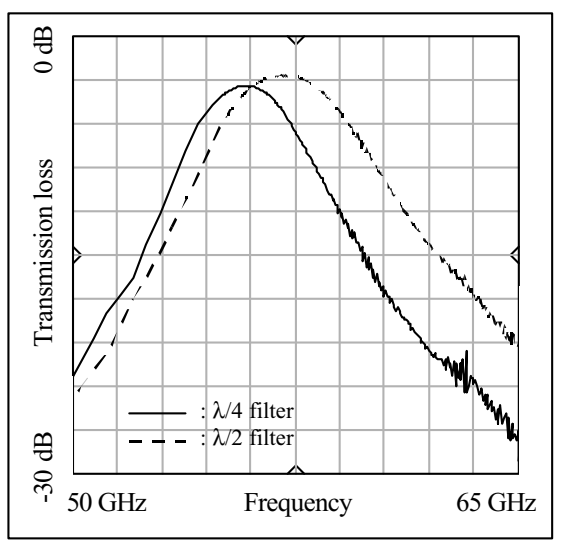

Figure 6. Comparison between measured transmission losses of $\lambda / 2$ and $\lambda / 4$ end-coupled filters.

Table 2. Comparison of second order filter performances for $\lambda / 2$ and $\lambda / 4$ resonators topology.

\begin{tabular}{|c|c|c|c|c|c|c|}
\hline Type & $\begin{array}{c}\mathrm{S} 21_{\mathrm{fo}} \\
(\mathrm{dB})\end{array}$ & $\begin{array}{c}\text { fo } \\
(\mathrm{GHz})\end{array}$ & Q1 & Qu & $\begin{array}{c}\text { Surface } \\
\mathrm{mm}^{2}\end{array}$ & $\begin{array}{c}\mathrm{S}^{2} 1_{\mathrm{fo}} \\
(\mathrm{dB})\end{array}$ \\
\hline$\lambda / 2$ & -2.7 & 57.7 & 14.7 & 55 & 7.6 & -33 \\
\hline$\lambda / 4$ & -3.5 & 55.8 & 16.6 & 50 & 3.5 & -25.7 \\
\hline
\end{tabular}

The advantage of the $\lambda / 4$ topology in term of bandwidth $(25 \%$ improvement $)$ and compactness $(50 \%)$ is significant. However, there is still a small difference between expected and measured data : additional work is actually in progress to improve the obtained performance and to demonstrate that this kind of filter fits most of the requirements for wireless on chip filtering.

\section{ACKNOWLEDGEMENTS}

The authors would like to thank particularly the technological staff of the LAAS-CNRS (Toulouse, France) for their great help.

\section{REFERENCES}

[1] P. Russer : "Si and $\mathrm{SiGe}$ millimeter-wave integrated circuits". IEEE MTT, vol. 46, n 5, pp. 590-603, may 1998 
[2] N.I. Dib, W.P. Harokopus Jr., L.B. Katehi, C.C. Ling, G.M. Rebeiz : "Study of a novel planar transmission line". IEEE MTT -S Digest 1991, pp. 623-626

[3] J.K.A. Everard, K.K.M. Cheng : "High performance direct coupled bandpass filters on coplanar waveguide". IEEE MTT, vol. $41, n^{\circ}$ 9, september 1993 , pp. $1568-1572$

[4] K. Sivanand, S. Uysal, K.W. Eccleston : "CPW bandpass filters using end-coupled quarter-wavelength resonators". Microwave and optical technology letters, vol. 15, $\mathrm{n}^{\circ} 1$, may 1997, pp. 29-33

[5] D.F. Williams, S.E. Schwarz : "Design and performance of coplanar waveguide bandpass filters". IEEE MTT, vol. 31, $\mathrm{n}^{\circ} 7$, july 1983, pp. 558-566

[6] K. Wada, I. Awai : "A $\lambda / 2 \mathrm{CPW}$ resonator BPF with multiple attenuation poles and its miniaturisation". IEEE MTT-S Digest 1999, pp. 1139-1142

[7] F-L Lin, R-B Wu : "Comparative performance of three different CPW bandpass filters". IEEE MTT-S Digest 1997, pp. $813-816$

[8] T.M. Weller, S.V. Robertson, L.P.B. Katehi, G.M. Rebeiz : "Millimeter and submillimeter wave microshield line components". $5^{\text {th }}$ International Symposium on Space $\mathrm{THz}$ Technology, pp. 802-810

[9] B. Guillon et al : "High performances micro-machined millimeter-wave structures". $28^{\text {th }}$ European Microwave Conference, Amsterdam, october 1998, pp. 690-694

[10] E. Saint Etienne et al : "A dedicated micromachined technology for high aspect ratio millimeter-wave circuits". Sensors and Actuators -A, vol. 68/1-3, 1998, pp. 435-441

[11] G. Matthaei, L. Young, E.M.T. Jones : "Microwave filters, impedance-matching networks, and coupling structures". Artech House, 1980

[12] P. Blondy, A. Brown, D. Cros, G.M. Rebeiz : "Low loss micromachined filters for millimeter-wave telecommunication systems". IEEE MTT-S Digest 1998, pp. 1181-1184 